\title{
A general equilibrium analysis of the economic impact of a reduction in harvest levels in British Columbia
}

\author{
by Clark S. Binkley ${ }^{1}$, Michael Percy ${ }^{2}$, William A. Thompson ${ }^{3}$, and Ilan B. Vertinsky ${ }^{3}$
}

\begin{abstract}
This paper examines the economic and social consequences of possible reductions in the Annual Allowable Cut (AAC) in the province of British Columbia. Following a review of studies of the role of the forest industry in the economy of British Columbia, a general equilibrium model is presented to examine the economic impact of AAC reduction where prices of forest products are allowed to fluctuate. While the studies reviewed and this study use different methodologies, the conclusion that emerges is robust: the economic impact of AAC reduction is significant and negative. The social costs in terms of unemployment and community stability/survival are even higher. The paper concludes with a set of recommendations intended to ensure that decisions concerning harvesting reflect comprehensively the costs and benefits involved in terms of the timber and non-timber values involved.
\end{abstract}

Cet article passe en revue les conséquences économiques et sociales découlant de la réduction potentielle de la possibilité annuelle de coupe (PAC) de la province de la Colombie-Britannique. Suite à une revue des études portant sur le rôle de l'industrie forestière dans l'économie de la Colombie-Britannique, un modèle général d'une situation en équilibre est présenté dans le but d'étudier l'impact économique de la réduction du PAC alors que les prix pour les produits forestiers peuvent fluctués. Bien que les études retenues et le cas présent utilisent différentes méthodologies, la conclusion qui émerge est évidente: l'impact économique de la réduction du PAC est significatif et négatif. Les coûts sociaux en terme de chômage et de stabilité/survie des communautés sont encore plus élevés. Cet article se termine par une série de recommandations destinées à s'assurer que les décisions touchant la récolte reflètent globalement les coûts et les bénéfices compris en terme de valeur de matière ligneuse et autres valeurs forestières.

\subsection{Introduction}

It is well known that the forest industry sustains a significant part of the economy in British Columbia. Forest exports exceed $\$ 3000$ for each person in the province (Forestry Canada, 1992). However, our knowledge of the economic impact that a reduction in the activity of the forest industry may have on B.C. is more limited. Several recent studies have suggested that the B.C. economy is highly vulnerable to a reduction in the economic activity of the forest industry (Horne, Paul and Riley 1991; Park 1991; Lax and Parker 1992). Few communities are likely to escape the adverse effects of reductions in harvest levels (Horne and Penner 1991; Park 1991).

Uncertainty with respect to the fate of the forest sector and the B.C. economy is high. Some of the uncertainty is unavoidable (e.g., market fluctuations, improved technical knowledge), but an important source of uncertainty is associated with changes in government regulation of timber harvesting. These changes are occurring in response to a declining supply of old growth forests and changing public valuation of these forests. Ensuring that government policy serves the common interest of the people of B.C. requires a careful calculation of both the benefits and costs of new regulations. This paper addresses some of the costs of associated with policies which reduce the timber supply in B.C.

The availability of wood is perhaps the most important short-term determinant of industrial activity in the forest sec-

\footnotetext{
${ }^{1}$ Faculty of Forestry, University of British Columbia, Vancouver, British Columbia Canada.

${ }^{2}$ Department of Economics, University of Alberta, Edmonton, Alberta, Canada.

${ }^{3}$ Forest Economics and Policy Analysis Research Unit, University of British Columbia, Vancouver, British Columbia, Canada.
}

tor. It is jointly determined by physical availability of timber, the economics of supply and demand, and government regulation of wood production. In B.C., timber harvesting from Crown lands (circa 95\% of the province's forest land) is regulated through the determination of an Annual Allowable Cut (AAC). The AAC is the volume of timber which may be cut each year. ${ }^{1}$ It is supposed to be consistent with the policy objective of sustained yield. However, sustained yield is not easily determined because it depends upon a variety of factors, including: forest growth rates; harvesting and processing technologies; and regulatory constraints on harvesting.

In practice, the AAC is set by the Chief Forester, and it reflects a variety of concerns which influence the rate of timber production that may be sustained. These include for each management unit: (1) forest composition and growth rate; (2) forest re-establishment rate following harvest; (3) silvicultural treatments; (4) timber utilization standards and allowance for decay, waste and breakage; (5) constraints on timber production from competing uses; and (6) other pertinent information. Both the shortand long-term implications of alternative rates of harvesting and the timber requirements of established and proposed processing facilities must be considered. Finally, the Chief Forester also must consider the economic and social objectives of the government. While the process includes specific, detailed calculations, Hoberg (1993, p. 35) observed on the basis of personal interviews with staff of the B.C. Ministry of Forests that the "AAC is the result not of specific calculations but of general discretion".

The B.C. Forest Act was amended in 1992 to allow "...for

\footnotetext{
${ }^{1}$ While the actual timber harvest can be less than the AAC, in recent years the two have been nearly equal. In this paper we assume that the AAC will continue to be a binding constraint upon harvest levels. Thus, we use AAC reduction as equivalent to harvest level reduction.
} 
more careful planning that balances the economic, recreational and environmental benefits that [are] expected from ... forest resources..." (Miller, 1992). The amendments require that new AACs for all Crown forest lands be determined by December 31, 1995 and every five years thereafter.

This accelerated timber supply review has generated considerable uncertainty about future AAC levels. The review calculates sustainable yields which reflect current practices and regulations rather than projected historic trends and includes an array of environmental constraints. These constraints provide one major source of uncertainty with regard to AAC levels. Other major sources of uncertainty (and controversy) are the selection of growth and yield parameters for specific locations and the question of whether various constraints on harvesting are indeed beneficial in terms of their ultimate environmental outputs ${ }^{2}$.

The timber supply review has been going for over a year now. Based on reviews completed to date and announced AAC reductions, many regions may experience AAC reductions of 10-30\%. These reductions will have significant economic impacts on province. In the following section we review estimates of the province-wide economic impact of AAC reductions. The third section presents a new model for assessing those impacts. The fourth section compares our results with those of other studies. In the fifth section we discuss the distribution of those impacts across the province. The final section presents policy implications of these impacts.

\subsection{Economic Impact Assessment}

A key consideration in public forest policy is the economic impact on the province and specific regions of alternative levels of AAC. Several methods are available for assessing that impact. We will discuss three: input-output models, policy simulation models, and general equilibrium models. A brief summary of some of their differences is presented in Table 1, with elaboration in the text below.

\subsection{Input-output Model}

Several studies of the economic impact of the forest industry in B.C. were based on input-output (IO) models (Ministry

Table 1. Characterization of three economic impact assessment models for British Columbia

\begin{tabular}{lccc}
\hline Attributes modelled & Input-output & $\begin{array}{c}\text { Policy } \\
\text { simulation }\end{array}$ & $\begin{array}{c}\text { General } \\
\text { squilibrium }^{\mathbf{3}}\end{array}$ \\
\hline Time & no & yes & no $^{4}$ \\
Subsitution & no & yes & yes \\
Price response & no & no & yes \\
Transfer payments & no & no & yes \\
Intersectoral linkages & yes & yes & yes \\
Regional differences & no & no & yes \\
Supply constraints & no & yes & yes \\
Wages & no & yes & yes \\
Inter-provincial migration & no & yes & no \\
\hline
\end{tabular}

${ }^{1}$ Horne, Paul and Riley (1991).

${ }^{2}$ Lax and Parker (1992).

${ }^{3}$ This study.

${ }^{4}$ It is possible to formulate a simulation model starting from the same equations.

${ }^{5}$ Wages can vary, but sector output prices are exogenous.

${ }^{2}$ The review does not include an evaluation of the appropriateness of the constraints. of Finance 1990; Horne, Paul and Riley 1991). When applied to an open economy, IO shows the income relationships which exist between sectors of a particular geographical area (e.g., region, province) and external "trade" links with other economies (other regions, provinces, and countries), permitting inferences concerning the economic interdependence of the various activities within the economy (Bromley et al. 1968; Richardson 1985; van Kooten, 1993a). The IO model ensures that any change in the activity of one sector is reflected in the activities of the sectors which supply it. While the IO model is based on comparative statics, it shows the full magnitude of adjustment in the economy.

Several limitations of the IO model emerge from its assumptions and design characteristics. As the model is static, no assessment is provided of the time path of the adjustment (e.g. how fast do the various sectors change? when are their impacts felt?). The IO model assumes no capacity constraints on production, no scale effects, no substitution of factor inputs, and, therefore, no impacts of changes in relative prices. Further, IO models fail to capture the role of transfer payments which are uncorrelated with industrial activity levels and assume that government activities and investment are independent of the industrial activity (although, in practice, both governments and investors modify their behaviour in response to the economy).

The B.C. Ministry of Finance and Corporate Relations (hereafter Ministry of Finance) used an IO model to assess the role of the forest industry in the provincial economy (Ministry of Finance, 1990). The study estimated effects attributable to industry activities as a percent of total provincial employment. The employment share attributed to forest industry final demand was $4.5 \%$. Indirect and induced impacts within the forest sector accounted for $2.5 \%$ of provincial employment, while indirect and induced employment in other sectors accounted for $8.4 \%$ of provincial employment. The total share of the provincial employment driven by forest activities was estimated to be $15.4 \%$ in 1984 . Thus, the employment multiplier was 2.2 ; that is, for each job in the forest sector 1.2 additional jobs were created in the economy. The study also identified those sectors in the economy whose total employment effect is larger than the actual employment as economic "drivers". As $7.0 \%$ of the total provincial employment for 1984 was in the forest sector while the total employment effect of the sector was $15.4 \%$ of the provincial labour force, the forest sector is one of the province's most important economic "drivers".

In a second IO study, Horne, Paul and Riley (1991) estimated the impact of a hypothectical reduction in raw material supplies to the forest industry. As the IO model assumes no supply constraints, the additional assumptions were made that a reduction in log supply would lead to a proprortionate reduction in forest-related industrial activity, and that the reduction would be uniform across regions and subsectors of the industry. The study ignored potential benefits of such a reduction to other sectors (e.g., tourism). A reduction in the activity of the forest industry produces four kinds of impacts: (1) direct, indirect, and induced impacts, (2) impacts on investment, (3) impacts on the transportation and wholesale sectors, and (4) impacts on industry activities which support other industries. The total estimated impact of $10 \%$ reduction in AAC in 1989 as a percent of total provincial activity was a reduction of employment by $2.2 \%$ and a decline of $2.5 \%$ in the GDP. In 1989, total employment 
in British Columbia was $1,435,000$, and GDP was $\$ 76.3$ billion (Forestry Canada, 1992). Therefore, the forecasted reductions were the additional unemployment of 31,570 people and a $\$ 1.9$ billion loss to the provincial GDP.

\subsection{Policy Simulation Model}

Impact estimates derived from IO models do not provide information on the timing of the impacts or the long term adjustments that can take place in the economy as it adapts to the changes in sectoral activities. Lax and Parker (1992) used the B.C. Econometric Policy Simulation Model to evaluate the time path of impacts and the consequences of alternative implementation policies of reductions in the AAC. Their simulations included changing investment patterns, flexible wage rates, substitution of labour and capital, and interprovincial and interindustry labour mobility.

They modelled B.C. as an open economy with four broad sectors: firms, households, government, and the external sector. The forest sector was divided into three subsectors: primary forestry (logging), wood processing and paper and allied industries. The study assumed: (1) the industry as a whole is a price taker (i.e., forest product supply decisions in B.C. do not affect prices); ${ }^{3}$ (2) the use of 1981 dollar value of output as a proxy for physical output; (3) the use of a constant ratio of production to timber supply (i.e., higher fibre costs would not affect the efficiency of fibre utilization and substitution); (4) a production function with constant returns to scale; and (5) a moderate rate of increase in real prices of forest products.

The study examined the impacts on GDP, investment, employment, unemployment, and government fiscal position of several AAC scenarios, one of which (their scenario 2, a 25\% reduction in AAC) corresponds well with the other studies discussed here. Results were expressed as the percent change from a base scenario involving constant harvest levels. The model predicted that a rapid AAC reduction to $25 \%$ below the 1991 level would reduce GDP $8.5 \%$ by the year 2001 . The negative impact would peak in 1997 at almost $10 \%$ below the GDP of the base case, recovering steadily thereafter to approximately $6 \%$ lower GDP than the base case by 2011 . The forecasted employment impacts were lower since the model projected a movement of employees who lost their jobs in the industry to other sectors or other provinces.

\subsection{General Equilibrium Models}

The major criticism directed at the studies described above is the handling of price changes. The IO model does not account for prince changes, and the policy simulation model treats forest products prices as exogenous. One approach to account more explicitly for market forces is to use a general equilibrium (GE) model of B.C. as an open economy.

Descriptive measures of the forest industry, such as employment and contribution to GDP imply that the industry is indispensible to B.C. However, such measures provide no insights into the opportunity cost of the factors employed in the industry and implicitly assume that they have no alternative use in the economy. However, to the extent that the labour and capital presently employed in the forest industry can be reallocated to other sectors of the provincial economy with no decline in real wages and rental rates of the capital and resource inputs, the descriptive measures exaggerate the importance of the forest industry.

GE models were originally introduced by Johansen (1960) as a method to account for the opportunity costs of the factors employed in an industry and incorporate the full range of inter-industry linkages while satisfying the constraints imposed by economic theory. They permit the prices and quantities of commodities/inputs, labour and capital employed in the economy to vary with respect to changes in output prices and production. GE models are commonly expressed in proportional rate of change format. This formulation has modest data requirements, is computationally simple, provides results interpretable in terms of elasticity relationships, and suits the economic analysis of policy shocks (Prins 1990).

A problem for modelling the forest industry in B.C. arises from the "openness" of regional factor markets. The migration of labour between provinces depends upon its real wages relative to those in other regions. In addition, provincial capital markets are highly integrated with national and international markets. Thus, the opportunity costs of these factors are not determined within B.C.

Given the long-run mobility of labour and capital, the solution to modelling the B.C. economy was to develop two separate models based on different assumptions regarding factor mobility: short-run and long-run models. In this paper we present the short-run model, as it is most comparable to the other models discussed above. The short-run model assumes that labour is mobile between sectors but not between regions and that capital is not mobile between sectors.

\subsection{A General Equilibrium Model of the B.C. Economy}

The GE model used is an updated version of Percy's (1986) model incorporating more recent data and a modified production function in the forest industry where land cannot be substituted by capital or labour. The GE model includes nine sectors, five of which are used to represent the forest industry. The forestry sector is disaggregated to account for regional differences between products, production technology, and factor and output prices.

The first two sectors, Coastal and Interior timber harvesting, produce timber whose primary markets are the B.C. solid wood products and B.C. pulp and paper sectors (government regulations restrict the export of unprocessed logs). The timber harvesting industries use labour, purchased intermediate good, sector-specific capital ${ }^{4}$ and forest land as inputs. The third and fourth sectors are the Coast and Interior solid wood sectors, whose primary products are softwood lumber and wood chips. It was assumed that the input of logs to the Interior wood products sector is exclusively from Interior logging and that Coastal wood products use logs only from Coastal logging. Other inputs are labour and sector-specific capital. The lumber output from the two sectors goes to domestic and export markets, while the chips go to the fifth sector, the B.C. pulp and paper sector. Production from this sector goes primarily to the export

\footnotetext{
${ }^{3}$ This assumption is questionable. Although each B.C. firm in the industry is a price-taker, B.C. is a major international producer of many forest products.
} 
market. Its inputs are labour, sector-specific capital and purchased intermediate inputs: logs from the two logging sectors and chips from the two wood products sectors. Although this sector was not regionally differentiated, the inputs of logs and chips differ between regions.

The sixth sector is composed of other primary products, the renewable and nonrenewable resource industries (including agriculture, fishing, mining and energy). This sector relies heavily on world markets and faces highly elastic demand for its output. The seventh sector consists of the nonforestry manufacturing industries. Imports create significant competition for this sector, but domestic manufactured goods are treated as imperfect substitutes for imports, modelled as an Armington (1969) effect. Thus, prices for domestic manufactured goods are endogenous to the model. The eighth sector is composed of nontraded industries (e.g., retail and wholesale trade), housing and personal service industries. Demand for the output consists of final demand and intermediate use demand by other industries. As the output is consumed in the region in which it is produced, prices are determined within the provincial market. The ninth sector is government, modelled separately from other service industries because the two differ in production technology. The government sector produces publicly-provided, private goods using labour, sector-specific capital and intermediate inputs. Its output is treated as if sold on a fee-for-use basis.

Wages were assumed to be fixed in the short-run. Under this assumption the labour market adjusts through changes in unemployment or labour force participation rates. Both capital and land are treated by the model as being sector specific and fixed for the short-run. Forest land receives special treatment. It is a primary input to the Coastal and Interior timber harvesting sectors, but its supply is completely inelastic, being set by government regulation through the AAC. In the shortrun model, it was assumed that there are no substitutes for forest land. Thus, changes in forest production technology (e.g., silvicultural investments) or land use (e.g., expansion of the commercial forest land base to include currently uneconomic forest lands) are exluded.

The model was formulated as a system of thirty-eight equations. Linearization, differentiation and rearrangement of terms yielded a mathematical expression of the form $\mathbf{A q}=\mathbf{b}$, where $\mathbf{A}$ was a matrix of parameters, $\mathbf{q}$ was a vector of changes in endogenous prices and quantities, and $\mathbf{b}$ was a vector of changes in exogenous policy variables. Thus, $\mathbf{q}=\mathbf{A}^{\mathbf{- 1}} \mathbf{b}$ computes the impacts of the changes in the exogenous variables, where $\mathbf{A}^{-1}$, the matrix inverse of $\mathbf{A}$, is a matrix of impact multipliers. Percy (1986) provides further details.

Parameter values for the model were updated from the initial formulation (Percy 1986) using 1989 data (B.C. Ministry of Finance, 1992). For timber production, the use of sectoral data for 1989 reflected changes made in 1987 to the stumpage system, including reforestation requirements. In cases where published data were not available for the Coast and Interior separately, regional estimates were based upon the size of the labour force or industry capacity.

The demand elasticities for solid wood products and for pulp and paper are key parameters in the GE model. A recent summary of published estimates of U.S. excess demand elasticities for Canadian softwood lumber (Phelps, 1993) indicated a range from -0.23 to -0.82 with an average of -0.48 . In other literature we found estimates as high as -2.65 (Constantino and
Percy 1991) and as low as -0.17 (Loewen, 1992). Given this wide range of excess demand elasticities for Canadian wood products in the U.S. and our lack of knowledge of demand elasticities in other export markets, we provide results of the GE model for elasticities of -0.5 and -2.0 . The excess demand elasticity for pulp and paper is probably higher since the B.C. market share for pulp and paper is lower than that for solid wood products, but, lacking comparable data, we used the same two elasticities. Finally, for comparison with the fixed price assumptions of the IO and policy simulation models and illustration of the short-run importance of these demand elasticities to the B.C. economy, results were computed with infinite elasticities for both wood products and pulp and paper.

Estimated impacts were calculated for AAC reductions of $10 \%$ and $25 \%$. These AAC reductions were apportioned between regions based upon estimates of the relative severity of anticipated reductions: $12.5 \%$ and $31.3 \%$ for the Coast; $8.8 \%$ and $22.0 \%$ for the Interior, respectively. The results for a $10 \%$ reduction are given as changes to the base case of no reduction in Table 2. The model predicted that the impact of a reduction of $10 \%$ in harvest levels on employment would range from +1.5 to $-2.4 \%$, depending upon one's assumptions for the U.S. excess demand elasticities for B.C. solid wood products and pulp and paper products (Table 2). Real GDP would decline by 2.6 to $4.8 \%$. The results for a $25 \%$ reduction in the AAC were correspondingly larger: reductions of $7.5 \%$ in GDP and $4.0 \%$ in employment assuming both elasticities to be -2.0 . If we assume that the provincial output has no effect on international prices, the estimated impact of a $25 \%$ reduction in AAC would be reductions of $6.5 \%$ in GDP and $6.0 \%$ in employment.

Generally, the more inflexible wages are, the greater are the costs associated with an AAC reduction, even when much of the direct costs can be passed on to foreign purchasers through higher prices. While the negative impacts of an AAC reduction can be mitigated somewhat if market adjustment mechanisms operate without constraints, such market adjustments - lower wages and retraining - pose social costs which these models do not reflect. Finally, the model does not account for the high costs of the transition process and the high barriers to labour mobility that the geographical pattern of the forest sector imposes.

\subsection{Model Comparison}

Table 3 summarizes the results from the three models: IO, policy simulation and GE. Note first that, when the assumption

Table 2. Social and economic impacts of reductions in the AAC (given as \% changes from base case of no reduction)

\begin{tabular}{|c|c|c|c|}
\hline \multicolumn{4}{|c|}{ Employment } \\
\hline \multirow{2}{*}{$\begin{array}{l}\text { U.S. Excess Demand } \\
\text { Elasticity for B.C. Pulp } \\
\text { and Paper Products }\end{array}$} & \multicolumn{3}{|c|}{$\begin{array}{l}\text { U.S. excess demand elasticity for B.C. } \\
\text { solid wood products }\end{array}$} \\
\hline & -0.5 & -2.0 & $-\infty$ \\
\hline-0.5 & +1.5 & -1.4 & -2.4 \\
\hline-2.0 & +0.5 & -1.6 & -2.4 \\
\hline$-\infty$ & -1.3 & -2.0 & -2.4 \\
\hline \multicolumn{4}{|c|}{ Provincial GDP } \\
\hline-0.5 & -3.6 & -2.8 & -2.6 \\
\hline-2.0 & -4.1 & -3.0 & -2.6 \\
\hline$-\infty$ & -4.8 & -3.4 & -2.6 \\
\hline
\end{tabular}




\begin{tabular}{lcc}
\hline Table 3. Economic impact of AAC reductions without price response \\
\hline & Employment & GDP \\
\hline 10\% reduction & & \\
Horne, Paul, and Riley (1991) & $-2.2 \%$ & $-2.5 \%$ \\
FEPA GE Model: $-\infty$ & -2.4 & -2.6 \\
$25 \%$ reduction & & \\
Lax and Parker $(1992)^{2}$ & $-4.8 \%$ & $-8.4 \%$ \\
FEPA GE Model: $-\infty$ & -6.0 & -6.5 \\
\hline
\end{tabular}

${ }^{1}$ Excess demand elasticities for solid wood products and pulp and paper products.

${ }^{2}$ Forecast for the year 2001

that B.C. producers are price-takers is maintained, there is a reasonable level of agreement between the GE model and the other studies. Second, the results are linear with respect to changes in AAC - doubling the reduction doubles the employment and GDP impacts. Third, the results, particularly for employment, are sensitive to the value of the excess demand elasticity for B.C.'s forest products. This highlights the importance of including price responses in models for economic impact assessment and the consequent need for better data on foreign excess demand for B.C. forest products. Because B.C. is a major international producer of softwood lumber (accounting for about $30 \%$ of total international trade in this product) and to a lesser extent market pulp (about 20\%) and newsprint (about 10\%) (Forestry Canada 1992), significant changes in production levels in B.C. may affect international market prices. The precise magnitude of the effect is not well understood, particularly for market pulp and newsprint.

\subsection{Additional Socio-economic Impacts}

The discussion above focused on just two socio-economic impacts of reduced timber harvesting in B.C., reductions in GDP and in employment. The distributional consequences of these impacts are important issues. The methods presented above do not address these concerns, but other studies have examined them.

When one considers the fate of many communities which depend upon the forest industry and the high adjustment costs involved in the destabilization of these communities if harvest levels are reduced significantly, a more pessimistic view of the potential impact of reductions in the level of AAC is revealed. Horne and Penner (1992) found that more than a quarter million people in B.C. live in communities where the forest sector is accountable for $40 \%$ or more of the income generated by basic sectors and almost half a million people in B.C. live in communities where more than a quarter of the income derived from basic sectors originates in the forest sector. Thus, a significant reduction in the activities of the forest industry in these communities is likely to destabilize them, perhaps to the point that they disappear altogether.

The lack of diversity in many local economies means few opportunities for coping with reduction in activity levels in the industry except for uprooting and moving to major urban centres or leaving the province. The opportunities in the urban centres may not, however, be so promising if the activities in the forest industry decline (Berck et al., 1992).

Though perhaps less visible, the forest sector plays also a dominant role in the economy of the metropolitan Vancouver area. Excluding the impact of provincial government expenditures, Park (1991) estimated the economic impact of the B.C. forest industry in the metropolitan area of Vancouver for
1989 to be $\$ 6.0$ billion of GDP and 115,000 jobs with wages and salaries of $\$ 3.0$ billion.

\subsection{Policy Implications}

Public policy related to setting AAC for the province depends on understanding the consequences of alternative harvest levels. Relevant considerations include the ecological effects on a wide range of terrestrial and aquatic organisms, and the economic effects on the province, including impacts on the forest sector, on other sectors such as tourism, and on the existence values people hold for landscape undisturbed by human activities.

In British Columbia where such a large fraction of the economic activity derives directly or indirectly from the forest sector, it is critical to understand the impacts of alternative levels of AAC on provincial GDP and employment. Current policy processes in place are apt to result in significant reductions in AAC, perhaps as high as $25 \%$. This level of harvest reduction could lead to a reduction in employment up to $6.0 \%(92,000$ people), a reduction of real GDP up to $6.5 \%$ ( $\$ 4.9$ billion), and a proportionate increase in the governmental budget deficit associated with reductions in tax revenues and increases in expenditures to provide services to these dislocated workers and communities. Much of this impact would be felt by the large fraction of the province's population that lives outside the lower mainland, but Vancouver would be affected strongly as well.

These estimates depend on information about forest products markets and the dynamic structure of the provincial economy that are not altogether certain. Research on the actual adjustment process that occurs as workers move from one industry to another, on the price elasticity of demand faced by B.C. as a whole, and on the interaction between reduction in $\mathrm{AAC}$ and changes in tourism would be quite useful.

A complete economic analysis would evaluate the economic benefits for non-timber uses associated with reductions in AAC. We have found very little quantitative information about these values. While there can be no doubt that the economic and social consequences of a substantial reduction in AAC are grave, it is also clear that the province must accommodate the increasing public demand for non-timber values that can be derived from the forest (van Kooten, 1993b).

Policies on harvest levels should consider all of the costs and benefits associated with alternatives. To do so, the AAC determination process should (i) table full information on the predicted economic impacts and non-timber benefits associated with all alternatives (including the current level of cut), and (ii) include sensitivity analysis to show the impact of specific environmental constraints and economic assumptions. This would permit decision makers and the public to understand the tradeoffs among timber and non-timber benefits associated with alternative levels of AAC.

In addition, the transition process that communities will undergo if harvest levels are reduced is poorly understood. To what extent can increased activities in secondary manufacturing absorb labour released from the primary sector? Can timber types that have been excluded from the analysis due to species composition or location be used to smooth the transition? How can increased investment in silviculture help offset possible reduction in AAC or provide important non-timber benefits? Answering these and similar questions is essential to responsible public forest policy in British Columbia. 


\section{Acknowledgements}

We wish to acknowledge the many experts whose generous assistance with this project was invaluable to us. While it is impossible to provide a complete list, we would like to recognize below some of those who provided us with invaluable comments and information: R. Addison, D. Alexander, R. Beaumont, D. Booth, H. Boydston, D. Bryan, J. Cuthbert, J. Deere, J. Elmslie, D. Errico, D. Fraser, H. Gairns, D. Gould, J. Hackett, D. Haley, R.L. Helfrich, G. Horne, L. Kiss, D. Larson, L. Lax, P. Legg, H. Lewis, B. MacArthur, J.N. MacFarlane, D. McMullan, J. Marritt, P. Pearse, C. Perry, R. Plecas, R. Prins, D. Rickson, V. Scoffield, D. Smythe, W.T. Stanbury, R. Stanyer, G. Townsend, R. Uhler, G.C. van Kooten, and M. Whybrow.

\section{References}

Armington, P. 1969. A theory of demand for products distinguished by place of production. IMP Staff Paper 16: 159-178.

B.C. Ministry of Finance. 1990. Sectoral Review of the British Columbia Economy. Ministry of Finance and Corporate Relations, Planning and Statistics Division, Quantitative Analysis Branch, Victoria, B.C.

B.C. Ministry of Finance. 1992. Economic Accounts 1982-1991. B.C. Ministry of Finance and Corporate Relations, Planning and Statistics Division, Quantitative Analysis Branch, Victoria, B.C.

Berck, P., D. Barton, G. Goldman and J. Geoghegan. 1992. Instability in forestry and forestry communities. pp. 315-338. In P.N. Nemetz (ed.) Emerging Issues in Forest Policy UBC Press, Vancouver, B.C.

Bromley, D.W., G.E. Blanch, and H.H. Stoevener. 1968. Effects of Selected Changes in Federal Land Use on a Rural Economy. Agricultural Exp. Sta. Bulletin 604. Oregon State University, Corvallis, OR.

Constantino, L. and M. Percy. 1991. The softwood lumber dispute and its impact on the economy of British Columbia. Unpublished report. Forestry Canada. 1992. Selected Forestry Statistics Canada 1991. Information Report E-X-46. Policy and Economics Directorate, Forestry Canada, Ottawa, ON. 231 pp.

Hoberg, G. 1993. Regulating forestry: A comparison of institutions and policies in British Columbia and the US Pacific Northwest. FEPA Working Paper 185. FEPA Research Unit, Vancouver, B.C. 137 pp.
Horne, G., N. Paul and D. Riley. 1991. The provincial economic impacts of a supply reduction in the British Columbia forest sector. In Forest Resource Commission Background Papers, Volume 4, Planning and Statistics Division, Ministry of Finance and Corporate Relations, Victoria, B.C. 32 pp.

Horne, G. and C. Penner. 1992. British Columbia community employment dependencies. In Forest Resources Commission Background Papers. Planning and Statistics Division, Ministry of Finance and Corporate Relations, Victoria, B.C. 39 pp.

Johansen, L. 1960. A Multisectoral Study of Economic Growth. NorthHolland Publishing Co., Amsterdam. 177 pp.

Lax, L. and J. Parker. 1992. The economic impacts of selected timber harvest scenarios in British Columbia. Forest Resources Commission Background Paper. Planning and Statistics Division, Ministry of Finance and Corporate Relations, Victoria, B.C. 30 pp.

Loewen, K. 1992. The Canadian lumber export market and its sensitivity to price and/or exchange rate changes. Unpublished report. Miller, D. 1992. Province of British Columbia News Release. B.C. Ministry of Forest, Victoria, B.C. July 11, 1992.

Park, D.E. 1991. The forest industry's role in Vancouver's economy. Vancouver Board of Trade, Vancouver, B.C. 73 pp.

Percy, M. 1986. Forest Management and Economic Growth in British Columbia. Report to the Economic Council of Canada, Ottawa, ON. 88 pp.

Phelps, S.E. 1993. A Summary of Elasticities of Demand and Supply for North American Softwood Lumber. Research Note, Policy and Economics Directorate, Forestry Canada, Ottawa, ON. 13 pp.

Prins, R.G. 1990. Global Factors Affecting the Canadian Forest Industry. M.Sc. Thesis, Department of Rural Economy, University of Alberta, Edmonton, AB.

Richardson, H.W. 1985. Input-output and economic base multipliers: Looking backward and forward. Journal of Regional Science 25: 607-660.

van Kooten, G.C. 1993a. Sustainable Development and Land Resources: Economic Policies for the Common Good. UBC Press, Vancouver, B.C.

van Kooten, G.C. 1993b. Economics of Protecting Wilderness Areas and Old-Growth Timber in British Columbia. FEPA Working Paper 189. FEPA Research Unit, Vancouver, B.C. 26 pp. 